\title{
La securitización de la política criminal postmoderna y lineamientos para un proceso de resistencia
}

Thereza Cristina Coitinho das Neves*

\section{Resumen}

Las políticas criminales postmodernas están, en gran parte, dotadas de una rigidez excepcional pero sin alcanzar resultados positivos en el combate al delito. Sin embargo, la sociedad las apoya convencida de que esa es la mejor forma de tener protegida su seguridad. Alarmada por los mensajes sensacionalistas propagados por los medios de comunicación, dicha sociedad legitima políticas fallidas e, incluso, socialmente nocivas, y acaba por exigir, de forma gradual, más dosis del mismo remedio (la represión penal). Sin embargo, dichas políticas no son eficaces pues se basan más bien en el temor social que en las causas del delito. Urge, por lo tanto, un proceso de resistencia al discurso securitizante, a fin de poner en práctica alternativas que logren una real disminución de la criminalidad. Aquí se plantea de qué maneras los actores sociales podrían resistirse a la securitización, a cuyo efecto se sugieren posibles estrategias que viabilicen dicha resistencia.

\section{Palabras clave}

Posmodernidad, Política Criminal, securitización, sectores sociales, resistencia.

* La autora es licenciada en Derecho (Universidade Salvador-UNIFACS, Brasil), Máster en Derecho Penal de la Universidad de Salamanca; candidata a Doctor en Derecho Penal de esta última casa de estudios. Se desempeña como asesora jurídica de la Fiscalía Federal en Salvador, Bahía. Dirección electrónica: teka248@hotmail.com 


\section{Introducción}

La Política Criminal postmoderna es, cada vez más, delineada en clave de seguridad, para dar cabida a un fenómeno llamado por algunos autores securitización. Muchas veces, con el auxilio de los medios de comunicación, los políticos logran que la sociedad legitime políticas estrictamente represivas, en razón de una supuesta protección a la seguridad social.

El discurso de que existe, cualquiera sea el objeto de referencia, una amenaza verdaderamente para la sociedad, posibilita que sean adoptadas medidas excepcionales para tratar de erradicarlas como principales estrategias de diversas políticas criminales. Dichas políticas pasan a ser deformadas, flexibilizándose los principios del Derecho penal democrático, y dejándose atrás los avances de la Criminología en el estudio de la respuesta al delito. Los resultados de ese proceso son verdaderamente caóticos, una vez que los actos de represión penal justificados más bien en un temor social que en datos científicos, además de no contener las cifras delictivas, limitan un debate abierto y legítimo respecto de las causas de algunos fenómenos criminales y aún traen situaciones de verdadero riesgo a muchas comunidades. Todo eso acaba por generar cada vez más, justamente, lo que se dice combatir: la inseguridad.

Por tratarse de un proceso político, que envuelve a diversos actores sociales, en un círculo vicioso a través del cual se movilizan discursos y prácticas convenientes a los sentimientos de la sociedad, se torna muy difícil su deconstrucción. Sin embargo, es necesario buscar otras alternativas, toda vez que la mayoría de estas políticas son ineficaces y traen con ellas diversas consecuencias negativas en muchos ámbitos de la convivencia en sociedad.

Siendo así, con base en estas anotaciones previas, el presente artículo tiene por objetivo plantear algunas estrategias de resistencia por parte de los propios actores sociales al proceso securitizante. Por lo tanto, inicialmente, se contextualiza dicho proceso en el momento histórico actual y se delimita un concepto que describa ese fenómeno a fin de dejar claro cuál es el objeto del presente texto. Enseguida, se enumeran los efectos de las políticas criminales securitizadas, para demostrar la necesidad de un cambio de paradigma en el ámbito del control del delito. Finalmente, se sugieren algunas estrategias para resistir a la securitización, posibilitándose así abrir el camino para alternativas más eficaces en el combate del delito. 


\section{Securitización}

Para entender mejor el proceso que ciertos autores denominan securitización, que fundamenta un endurecimiento en el ámbito político-criminal en nombre de la seguridad, es interesante remitir a sus posibles orígenes, contextualizándole.

\section{Entorno.}

Observándose el panorama histórico-económico-social que envuelve el proceso securitizante, se pueden apuntar algunos aspectos que están estrechamente conectados con el fenómeno. Inicialmente, es posible citar el momento histórico en el que hubo una transición del paradigma de la libertad al de la seguridad. Conforme se observa, esa transformación coincide con el declive del Estado de Bienestar (Welfare State), surgido en el siglo XX después de la Gran Depresión ${ }^{1} \mathrm{y}$, más fuertemente, en el período de la posguerra en los Estados Unidos, Gran Bretaña y algunos otros países europeos, sobre todo los nórdicos, cuya prioridad era asegurar a los ciudadanos condiciones para una vida digna, de bienestar. Para ello, el Estado tenía un papel central en la regulación de la economía y promovía la justicia social, lo que nutría la confianza por parte de la sociedad en relación con las respuestas estatales.

Según Garland (2005, pp. 81-83), dicha confianza ha propiciado lo que él llama el welfarismo penal; tal modelo ha sido estructurado bajo el principio central de rehabilitación, seguido coherentemente por los operadores del sistema penal que actuaban de manera encadenada. Además, las instancias correccionales tenían un carácter individualizante, indeterminado y, en gran medida, discrecional, que posibilitaba que las autoridades penales trabajaran con más libertad a la hora de ajustar las respuestas a cada delincuente, de acuerdo con sus necesidades rehabilitadoras. Dicha indeterminación abría, entonces, una brecha de actuación, haciéndole creer al público que los elementos penales eran más fuertes de lo que de hecho se configuraban. Así, se lograban saciar las demandas punitivas de la sociedad y, al mismo tiempo, se podía fortalecer la toma de decisiones por los expertos y profesionales, que tenían en cuenta estudios criminológicos y empíricos sobre las causas del delito.

No obstante, a mediados de la década de 1970, hubo un giro en la opinión progresista en torno a las medidas correccionalistas. Se pasó a un discurso de desconfianza incesante en torno a la capacidad del 
Estado para promover el bienestar y controlar el delito (Garland, 2005 , p. 134). Eso, en razón de los cambios políticos, sociales y económicos que habían ocurrido a finales del siglo $\mathrm{XX}^{2}$; es decir, hubo una transformación en toda la estructura que daba sustento al control moderno del delito, basado en el welfarismo estadounidense y europeo.

De esta manera, el escenario económico pasó a ser protagonizado por el neoliberalismo, modelo de economía en el cual el Estado empieza a interferir mucho menos que en los tiempos del Estado de Bienestar, dándole más libertad a las iniciativas privadas y a la búsqueda del lucro. Todo eso, sin preocuparse tanto de las condiciones sociales igualitarias; sino, por el contrario, admitiendo la existencia de la exclusión social como ineludible (Brandariz, 2004, p. 51).

De esta manera, el desarrollo del capitalismo en su forma neoliberal, al desprenderse por completo del bienestar social como prioridad, provocó cambios en el control del delito cuyo ideal correccionalista cedió lugar a un imaginario retributivo y de mayor control social. Así, encubriéndose intereses también económicos ${ }^{3}$, fueron generadas las políticas de seguridad pero apenas en protección de los sujetos con los cuales el Estado obtuviera determinada renta. Así lo explica Böhm:

El sujeto protegido por las políticas de seguridad actuales es un animal rentable: sólo cuenta como cuerpo adinerado o endeudado, empleado, pagador de impuestos, en todos estos casos el Estado lo entiende económico y protegible. Quienes no son rentables para el Estado y los mercados (ni adinerado ni endeudado, desposeído, desempleado, indocumentado, rebelde, detractor) generan sensación de inseguridad. Las políticas de seguridad no dialogan con colectivos, con seres humanos socializados y socializables, con sujetos políticos entramados en las dinámicas sociales (Böhm, 2013a).

Así es que, con el nuevo sistema, se logra perpetuar una propuesta de exclusión social ${ }^{4}$ que es aun fácilmente promovida por el proceso de globalización, una vez que el globalismo traduce la ideología de la economía neoliberal, pues limita la mundialización al aspecto económico (a través del globalismo, se quiere que un Estado y todo su aparato social sean encarados como una empresa, como señala Beck (2001, p. 27)). Como se sabe, el proceso globalizante promueve una transnacionalización del capital, con operaciones que desbordan las fronteras de los países, permitiendo la libre circulación de bienes, personas y servicios. De esta forma, 
(...) la globalización introduce otras formas de riesgo o incertidumbre, especialmente las relativas a la economía electrónica globalizada, los riesgos de degradación medioambiental, los riesgos de tipo sanitarioalimentario, los derivados de la siniestralidad, los derivados de las patologías del presente, entre las que se incluyen las pandemias aún no superadas en cuanto a perturbaciones novedosas. El resultado es que el mundo en lugar de estar cada vez más bajo nuestro control está fuera de él. Es más, el progreso de la ciencia y la tecnología, que se suponía que harían la vida más segura y predecible para nosotros, tienen a menudo un efecto contrario (Pérez, 2007, p. 30).

De acuerdo con Beck (2008), vivimos actualmente en una sociedad del riesgo, que sería aquella en la cual "el trato con el miedo y con la inseguridad se convierten biográfica y políticamente en una cualificación civilizatoria clave" (p. 56). En tiempos denominados postmodernos, o de 'modernidad tardía' -conforme los suele llamar el sociólogo Garland ${ }^{5}$ - en los cuales vivimos hoy, es flagrante, como se ha visto, la remisión a la seguridad o a la falta de ella. Por eso ocurre que, a pesar de existir hoy, de hecho, nuevos riesgos, la sensación de inseguridad es más bien fabricada que real y no parece guardar fiel correspondencia con la realidad ${ }^{6}$.

Sin embargo, al elegir objetos de referencia, y con la ayuda de los medios de comunicación para promover el miedo y una sensación de vulnerabilidad, el poder político logra la legitimación social de criminalizaciones, bien como de otras medidas penales, incluso en carácter excepcional. Siendo así, delante de lo que se ha visto, el Estado contemporáneo, marcado por la economía neoliberal, es un modelo de Estado mínimo en lo socioeconómico y máximo en el control social (Pérez, 2007, p. 34). Por ello, Wacquant (2000), le atribuye las siguientes características al referido modelo estatal: "borramiento del Estado económico, debilitamiento del Estado social, fortalecimiento y glorificación del Estado penal" (p. 22). Es, pues, en ese contexto que se da la securitización de diversas políticas criminales, cuya noción se desarrolla en las siguientes líneas.

\section{Concepto.}

El concepto de securitization (securitización) ${ }^{7}$ ha permeado, inicialmente, las relaciones internacionales, según las líneas de investigación danesa e inglesa que le tenían por objeto de estudio (Buzan, Waever \& de Wilde, 1997). Con la incorporación de la línea francesa al Colectivo de Enfoques Críticos sobre la Seguridad en 
Europa ${ }^{8}$, se pasó a ver tal proceso también a través de los ámbitos sociológico y político, de la migración, criminológico y jurídico, de manera que la idea de securitización pasó a ser tratada no sólo dentro de las relaciones internacionales sino, también, en muchos otros campos incluido el sistema penal (Böhm, 2013a).

Así las cosas, si se tiene en cuenta que el objetivo del presente escrito es ese último ámbito citado, se debe trasladar el concepto de securitización, específicamente aplicado a las actuales políticas criminales. En este campo, en efecto, el proceso securitizante se desarrolla en unas fases que pueden ser simultáneas entre sî́.

En primer lugar, se elige un objeto de referencia. Es decir, se selecciona un tema conflictivo y los sujetos envueltos con determinada problemática, a fin de establecer una protección (o un discurso de protección) a la seguridad de éstos, como por ejemplo la tutela de los jóvenes en relación con las drogas. En ese caso, se plantea que es necesario proteger la salud de estos jóvenes indefensos en relación con el mal que traen las sustancias psicoactivas ilegales, que estaría acabando con la vida de millares de niños y adolescentes.

En ese punto, debe resaltarse que, a priori, cualquier asunto es securitizable; la gran cuestión es si los detentores del discurso securitizante están en un rango de poder que les permite llegar a una audiencia relevante. Ese es el otro paso del proceso: es necesario alcanzar a un público no solamente amplio, sino también que tenga el poder de hacer reclamos, sensibilizándolo sobre la vulnerabilidad de los sujetos que inevitablemente tendrán su seguridad amenazada (conflictividad transformada en un problema político), en caso de no tomarse una actitud enérgica y urgente en el ámbito penal (transformación de un problema político en un problema de seguridad).

Para lograr dicha transformación con éxito, los detentores del poder (políticos) se valen del apoyo de los medios de comunicación masivos $^{10}$ a fin de difundir la idea de miedo e inseguridad en la sociedad. Así, se pasa de utilizar una escala discursiva que transforma el problema de seguridad en verdadera amenaza existencial. De esa manera, la sociedad se ve sin otra alternativa que la de exigir de las autoridades estatales respuestas realmente fuertes, aptas para lidiar con una cuestión de vida o muerte. $Y$, como se sabe, el instrumento vendido como lo más fuerte por el Estado es el sistema penal ${ }^{11} \mathrm{y}$, así, se camina hacia la excepcionalización ${ }^{12}$ de medidas penales, fuertemente apoyada por la sociedad en general. 
Ante las consideraciones anteriores es posible, pues, delinear un concepto en torno al proceso securitizante en el sistema penal. La securitización en el ámbito político-criminal es, entonces, una técnica de gobierno de la que echan mano las autoridades estatales con elevado rango de poder (políticos), que, con la ayuda de los medios de comunicación, aireando el miedo y la inseguridad, logra una despolitización de los conflictos seleccionados, para los cuales se legitima una respuesta penal excepcional, una vez que el conflicto inicial se transforma, más que en una cuestión de seguridad, en una amenaza existencial.

\section{Efectos.}

Antes de ocuparse de este tópico es importante destacar que tal sistema, presente en el modelo de control del delito contemporáneo, trata más bien de rellenar lagunas políticas inherentes al contexto neoliberal; es decir, suplir la falta de políticas públicas serias en varios sectores que demandan una actuación positiva del Estado, en el sentido de proveer dignidad y bienestar ${ }^{13}$.

En razón de eso, conforme se ha dicho previamente, de forma contraria a los tiempos de welfarismo penal, no se tuvieron en cuenta los estudios empíricos y criminológicos respecto de las causas del delito a la hora de dibujar muchas de las políticas criminales. Eso, tal como era de esperarse, ha generado consecuencias muy dañinas a la sociedad, una vez que no se supo o quiso lidiar con los fenómenos criminales de manera racional. Dichas consecuencias pueden ser divididas en dos clases, que aquí se llamarán materiales y formales.

Las materiales, serían los impactos negativos causados en la sociedad en general que pasó a convivir en un ambiente de cada vez más riesgo e inseguridad; siendo ese, por lo tanto, el principal costo social de las políticas securitizantes. Además, tales políticas no lograron contener las cifras delictivas de los delitos objeto de estrategias securitizadas y la generación de una criminalidad subsidiaria fue flagrante. Remitiéndose al ejemplo de la política de drogas, la criminalización del narcotráfico ha producido otras fuertes modalidades de criminalidad, como el tráfico de armas, la corrupción y el blanqueo de capitales (Hulsman, 1987, p. 49).

Otra consecuencia dañosa a la sociedad fue, sin duda, la criminalización de la pobreza (Pérez, 2007, p. 35). A través de una política neoliberal, como se pudo ver, sólo se han profundizado la 
discriminación y la exclusión social. Los procesos securitizantes fueron complementarios en el sentido de que se pasó a segregar, de hecho, a algunos sectores sociales (como inmigrantes, drogadictos, terroristas, etc.), aislándoles en cárceles o en ambientes marginales.

Aún, hay que comentar del aumento vertiginoso ocurrido en los últimos años en la población carcelaria mundial. Conforme el ejemplo más que ilustrativo del tráfico de drogas, a partir de la entrada en vigor de la Nueva Ley de Drogas brasileña (Ley $11.343 / 2006)$, se computa un aumento masivo del número de presos relacionados con tal delito, que subió de 47.472 a 106.491 (124\%) en el período correspondido entre 2006 y 2010 (Marques de Jesús et al., 2011, p.15), aunque la nueva Ley haya quitado la respuesta de la prisión para la posesión de drogas para consumo propio.

Pero un impacto negativo material fue la falta de acceso a la información verdadera sobre el tema objeto de referencia de la política. Los discursos fundados en clave de seguridad han limitado enormemente la búsqueda de información de calidad respecto del delito por parte de la sociedad y de todo el proceso sociológico-cultural que lo envuelve, filtrando las que sólo interesan al mantenimiento de las propias políticas (así como del poder de sus promotores). A través de la propagación de informaciones distorsionadas, el gobierno impide no sólo una revolución social en contra de sus estrategias fallidas, sino que también consigue limitar bastante la evolución social, lo que sería inevitable mediante el libre acceso a informaciones basadas en evidencias científicas.

Un ejemplo bastante claro que demuestra esa última cuestión fue la restricción de investigaciones y experimentos científicos sobre las drogas consideradas ilícitas, impuesta por el prohibicionismo. Con una gradual flexibilización de esa política de drogas prohibicionista, se pudo, poco a poco, retomar investigaciones que estaban congeladas principalmente desde la época en que se dictó la War on Drugs (década de los 70 del siglo pasado), y en los últimos años se han descubierto, por ejemplo, grandes efectos benéficos del aceite de marihuana en relación con el cáncer (Gardner, 2013) y a la epilepsia (Ericson, 2013).

En ese punto, es importante comentar que la política de drogas, tan utilizada aquí como un gran ejemplo de política securitizada que genera diversas consecuencias dañosas, ha sufrido en épocas recientes cambios relevantes. En efecto, a finales de 2012 los esta- 
dos de Washington y Colorado legalizaron el comercio y uso de marihuana para fines recreativos y, para fines medicinales, ya se podía adquirir marihuana con receta médica en California desde 1996 (Araujo, 2014). Actualmente, más de una veintena de estados americanos legalizaron la marihuana medicinal (Globo.com, 2014) y existe un movimiento en el sentido de que todos los Estados Unidos regulen la marihuana de forma similar al alcohol y al tabaco (Drug Policy, 2014), a pesar de que la legislación federal aún se mantiene en la línea prohibicionista.

En ese panorama, Uruguay es el país pionero en legalizar (y, por lo tanto, regular) la producción, venta y uso de marihuana (La Vanguardia, 2014) devolviendo al área de la salud pública el tema que, desde hace un siglo, es tratado en el ámbito penal por medio de una política criminal securitizada. El modelo uruguayo de regulación del cannabis toma por premisa la de que el mercado de la droga ya existe (y siempre va a existir), debiendo el Estado regularlo y ofrecer políticas públicas para disminuir los riesgos y daños generados por su consumo abusivo, a través de la promoción de educación y salud.

Siendo así, teniendo por delante el giro que se ha dado en la política de drogas en Estados Unidos y, sobretodo, en Uruguay, cabe preguntarse: ¿estamos asistiendo, en últimas, a una propuesta dessecuritizante? Eso es lo que parece, al menos en la medida en que el Estado retira del sistema penal una cuestión que debe ser tratada con estrategias realmente eficaces que tengan en cuenta los aspectos científicos, históricos y sociales que envuelven el tema, volviéndolo a politizar. Se espera, desde luego, que el experimento a que se refiere el presidente uruguayo José Mujica sea llevado en serio e influya fuertemente en el cambio radical de muchas de nuestras políticas criminales. Mientras no se tengan a mano los resultados de la nueva política uruguaya, sólo nos resta retomar el asunto de los efectos de las políticas securitizadas.

Se puede citar, todavía, como consecuencia material de la securitización, el descrédito del sistema judicial y penal por parte de la sociedad, lo que genera una inestabilidad institucional. Aunque se compre la idea de que la mejor respuesta a una serie de conflictos es la penal, se desconfía que las instituciones investidas de poder realmente funcionen, una vez que, obviamente, no se asiste a una disminución de delitos; máxime si, por el contrario, la práctica de 
ellos sólo aumenta, en razón de no tomar las precauciones debidas, fundadas en las reales causas delictivas.

Por otro lado, se encuentran los efectos dañinos aquí denominados formales, una vez que impactan a la dogmática penal propiamente dicha, creándose enigmas cada vez más difíciles de resolver para el Derecho penal contemporáneo. Como ejemplos de ellos tenemos: la promulgación de nuevas legislaciones penales y procesales especiales; la tipificación de actos meramente preparatorios; la tipificación de delitos de peligro abstracto; socavamiento de principios del Derecho penal; la flexibilización de criterios de imputación penal; el debilitamiento de las garantías penales del individuo; la priorización de intereses colectivos antes que de los individuales, etc. (Pariona, 2009, p. 175). Obsérvese que estas medidas excepcionales muchas veces lesionan derechos fundamentales de los ciudadanos criminalizados ${ }^{14}$.

Por todo lo expuesto en el presente apartado, se puede concluir que son muchos los malos efectos del fenómeno de la securitización, por lo cual urge resistirlo.

\section{El papel de los actores sociales y lineamientos para un proceso de resistencia}

Conforme lo que se ha visto hasta entonces, la securitización en el ámbito político-criminal es un modelo que, al dislocar la respuesta política para el ámbito de seguridad, además de permitir violaciones de derechos y garantías constitucionales, no logra contener el delito. Así, promueve su propia retroalimentación ${ }^{15}$; pues causa justamente lo que se quiere combatir -la inseguridad-. En vez de rechazar las políticas criminales dominadas por el discurso securitizante debido a su flagrante ineficacia, la sociedad exige más recrudecimiento en las medidas penales, pues tiene enraizada la idea de que sólo a través del sistema penal se podrá combatir enemigos que representen una amenaza existencial.

Siendo así, uno se puede plantear, con cierta dosis de pesimismo, si ese sistema traería una "inercia imparable" (Barriuso, 2000, pp. 140-159) en la agenda política en relación con los delitos objeto de políticas securitizadas, no siendo posible el desmantelamiento de las estrategias construidas bajo un discurso de seguridad. Sin embargo, en el afán de que se proceda a un real cambio político-criminal, se entiende que, aunque no se tenga mucha idea de por dónde empezar, 
es necesario creer que ello es posible. Así, cabe preguntase: ¿de qué maneras se puede salir de ese círculo vicioso y promover el apoyo social a políticas públicas eficaces, que no se valgan de medidas penales excepcionales? Es con base en esa indagación, que se pasa a plantear estrategias que puedan viabilizar un proceso de resistencia al discurso securitizante.

La securitización, tal cual fue descrita anteriormente, requiere la actuación de algunos sujetos, llamados aquí actores sociales. De un lado, están los agentes políticos, detentadores del poder que quieren poner en práctica las políticas que les permitan mantener su status quo de poderosos; de otro, aparece la sociedad en general, también comprendidas en ella algunas autoridades institucionales, como jueces, fiscales, abogados, miembros de la academia, etc. Y, actuando en una plan de intermediación, se encuentran los medios de comunicación, responsables por hacer llegar los mensajes de los políticos a la sociedad y viceversa (aunque bien es verdad que esto último en menor grado).

El rol de los medios de comunicación es, por lo tanto, central, en el proceso securitizante (Coitinho das Neves, 2013). De esa manera, la primera estrategia a ser planteada consiste en una democratización de los medios de comunicación. No se trata de una tarea fácil, toda vez que son los políticos quienes detentan poder sobre los recursos mediáticos, pero aquí entra en juego un deber para los actores del órgano legislativo, que poseen gran poder de cambio en las distintas materias sociales, pues, como dice Larrauri (2006, p. 19), existe una suficiente base social para que el legislador se oponga al populismo punitivo.

Siendo así, se entiende que los países deben, en sus ámbitos internos, proclamar leyes que regulen estos medios ${ }^{16}$ combatiendo toda forma de monopolio mediático, y dándose posibilidades para que se emitan noticias diversificadas y de calidad. De esta forma, se estaría posibilitado el debate libre sobre diversos temas hoy securitizados, combatiéndose el sentimiento generalizado de inseguridad que ha sido fabricado por los medios de comunicación.

Otro paso para un proceso de resistencia sería la lucha por una repolitización de los diversos conflictos sociales que hoy están criminalizados, pero cuya respuesta, según indican algunos estudios criminológicos, sería más adecuada en otros ámbitos. En estos casos, la estrategia principal del Estado sería establecer políticas públicas 
asistenciales, de salud, educación, trabajo, mejor situadas en un ámbito administrativo, a fin de que fueran realizados y llevados a la realidad los derechos sociales de muchas minorías hoy segregadas por el sistema penal.

Una vez posibilitado el libre acceso a informaciones basadas en estudios y evidencias científicas, sin prevalecer la manipulación política de selección de noticias, no es ilógico pensar que la sociedad civil va a luchar contra las estrategias que no contemplen sus derechos ${ }^{17}$. Se aboga, aquí, por estrechar la relación entre los políticos y la sociedad civil, lo que puede ser posible a través de los movimientos sociales que exijan plebiscitos, más transparencia y una democracia directa.

Aún más: también parece interesante presionar al Legislativo para crear un cuerpo de expertos, dotados de poder, especializados en varias áreas que demanden políticas públicas, que puedan actuar como una especie de intermediarios entre los políticos y la opinión pública ${ }^{18}$. Esa estructura parece completamente necesaria, toda vez que ni los políticos ni la sociedad civil, pueden emitir respuestas frente a un fenómeno criminalizable, sin fundamentarse en las evidencias científicas que sólo un experto le puede proporcionar. Si hubiera una comisión integrada por técnicos en los parlamentos, que tuvieran derecho al voto y a interferir con peso en las reformas penales, eso sin duda aceleraría el proceso de resistencia a la securitización. No obstante, hay que pensar en cómo tornar factible la introducción de una comisión como la propuesta, que acabaría por limitar el poder político.

En la falta de la creación de leyes progresistas o de la introducción de un sistema que cuente con un cuerpo de expertos, aún es posible hablar de resistencia. No hay que perder de vista la importancia del papel de los que actúan en las diversas agencias que componen la red del sistema de justicia penal, pues son éstos quienes confieren efectividad a las decisiones legislativas. No se puede olvidar que, en el ejercicio de la persecución penal, los operadores jurídicos adoptan decisiones que tienen alcances político-criminales; por ello, es relevante que dichos operadores, como por ejemplo los jueces y fiscales, tengan la conciencia de que pueden, mediante su trabajo, aumentar o disminuir el punitivismo (De Carvahlo, 2010, p. 60).

Finalmente, se debe hacer referencia a una cuestión que pasa por la propia academia la cual, muchas veces, al estudiar el discurso 
securitizante, acaba por reforzarlo, una vez que lo reproduce sin ofrecer argumentos para su deconstrucción (Böhm, 2013a, pp. 1617). Por ello, el objetivo del presente artículo consiste justamente en indicar posibles formas que de hecho fomenten la adopción de nuevas políticas criminales. Siendo así, se espera que la comunidad académica se sienta invitada a realizar más producciones científicas sobre el tema, sin olvidar ofrecer alternativas para el discurso securitizante, pudiéndose, en fin, hablar de un verdadero proceso de resistencia.

\section{Conclusiones}

La política criminal postmoderna sufre, desde el declive del Estado de Bienestar, un proceso denominado securitización. Contextualizado en los ideales neoliberales, tal fenómeno ha logrado el recrudecimiento del tratamiento penal de diversos delitos. La sociedad, embriagada por el discurso securitizante propagado por los medios de comunicación, legitima la adopción de medidas penales excepcionales en razón de un clima de inseguridad y miedo.

Ocurre que, al ignorar las reales causas de los delitos, dicho fenómeno no consigue controlar las cifras delictivas, causando, todavía, consecuencias dañosas a la sociedad. Así, no solo se multiplica la inseguridad sino que se legitima un Derecho penal excepcional direccionado a eliminar las amenazas existenciales.

Una vez descrito el referido panorama, aquí se intentan trazar algunos lineamientos para adelantar todo un proceso de resistencia frente al fenómeno securitizante, a fin de posibilitar la adopción de políticas criminales alternativas basadas en evidencias científicas, y no en el mero temor social. De esta forma, se sugieren las siguientes estrategias: democratización de los medios de comunicación, posibilitándose el libre acceso a la información de calidad; la movilización de la sociedad civil en la lucha por sus derechos; la repolitización de diversos conflictos securitizados, con el establecimiento de políticas públicas fuera del ámbito penal; la creación de una estructura estatal que soporte un cuerpo de expertos con el poder de intermediación entre el gobierno y la opinión pública, para la adopción de políticas criminales que demuestren ser, de hecho, eficaces; concienciar tanto a los integrantes del órgano legislativo como a los operadores jurídicos sobre su papel determinante a la hora de incrementar o disminuir el punitivismo; $y$, por fin, la concienciar a la academia en torno a la manera de abordar 
el fenómeno securitizante, a fin de proponer más alternativas que ayuden a combatir el fenómeno, huyéndose de la mera reproducción de su discurso que, como se pudo ver, es extremamente perjudicial para el bienestar general.

\section{Notas}

1 Se denomina "Gran Depresión" o "Crisis de 1929" al peor período de recesión económica (que ha durado de 1929 hasta el final de la Segunda Guerra Mundial) por el cual han pasado los Estados Unidos y cuyos efectos se han sentido en todo el mundo.

2 Garland (2005, p. 141) sintetiza dichos cambios en cuatro epígrafes: "(1) la dinámica de la producción capitalista y del intercambio de mercado y los correspondientes avances en la tecnología, el transporte y las comunicaciones; (2) la reestructuración de la familia y el hogar; (3) los cambios en la ecología social de las ciudades y los suburbios; (4) el surgimiento de los medios electrónicos de comunicación y (5) la democratización de la vida social y cultural".

3 Es importante no perder de vista que el giro al paradigma de la seguridad, así como cualquier política pública, esconde determinados intereses de quién detenta el poder. De acuerdo con la reflexión de Garland (2005, p. 141), el actual control del delito es fruto de "un proceso complejo en el que siempre entran en juego visiones diferentes de los problemas y las soluciones, así como intereses y sensibilidades distintos".

4 "Se construye socialmente el control y la vigilancia como obsesiones, y la segregación (de grupos de riesgo), la fortificación y la exclusión como urgencias" (Pérez, 2007, p. 34).

5 El autor (Garland, 2005, pp. 140-141) cuenta que, en verdad, llama a este estadio como modernidad tardía por conveniencia; no obstante, atendida la vaguedad del término, prefiere llamarlo más bien como "modernidad de fines del siglo XX" que es más específico, además de no dar por supuesto que estamos llegando al final o al punto más alto del proceso de modernización.

6 Según Díez (2005, p. 4), eso ocurriría por tres razones: la cobertura mediática, que sobre ilumina los hechos delictivos; la dificultad del ciudadano medio para comprender el acelerado cambio tecnológico; $\mathrm{y}$, la generalización de la percepción social de que la sociedad tecnológica conlleva una transformación de los valores y una disminución de la solidaridad colectiva.

7 Que consistiría, según la traducción de Böhm (2013), en "procesos en los cuales el 'acto de habla' de etiquetar un tema en forma social y 
políticamente exitosa como un 'tema de seguridad', desplaza a este tema de seguridad del ámbito normal de la política del día a día, colocándolo como 'amenaza existencial', que evoca y justifica medidas extremas"; el original inglés, en Williams, 1998, p. 435.

8 Originalmente denominado C.A.S.E. (Critical Approaches of Security in Europe), que era un colectivo de estudios realizados por investigadores activos conformado en Europa después de la publicación de la obra "Security: a new framework for analysis".

$9 \quad$ En ese punto, se remite a la caracterización del proceso securitizante en el ámbito del sistema penal y sus fases, que hace Böhm, 2013a, pp. 12-13.

10 Hoy existen algunas líneas de investigación ya consagradas en el escenario criminológico, que estudian justamente el rol de los medios de comunicación en un proceso de recrudecimiento penal, como el 'Populismo Punitivo' (L. F. Gomes) y la 'Criminalidad Mediática' (E. R, Zaffaroni).

11 Se dice, entonces, que "supone una cohesión que, ante una sensación que ya no es de angustia, sino propiamente de miedo, revierte de nuevo en exigencias específicamente normativas hacia el Estado, el cual, pese al carácter novedoso de la nueva amenaza, puede desenvolverse en el "cómodo" y conocido campo semántico de la amenaza criminal" (San Martín, 2006, p, 71 y ss.). De todos modos, se debe tener en cuenta que "sólo es securitizable con perspectivas de éxito un tema sobre el cual pueden ofrecerse pretendidas soluciones de corto plazo. Procesos securitizantes que requieran largos términos para la neutralización de la temida amenaza existencial, no resultan políticamente sostenibles, ni rentables", siendo la criminalización un proceso rápido, y el sistema penal una estructura portadora de importante carga simbólica, que sacia, sin demoras inadecuadas, las demandas punitivas de la sociedad (Böhm, 2013a, p. 9).

12 Por ejemplo, la expedición de leyes penales especiales para determinados sujetos que permitan la violación de derechos y garantías procesales asegurados por los procesos regulares.

13 En ese sentido, diserta Pérez (2007): “Se antepone el valor de la seguridad a cualquier otro valor utilizándolo como pretexto para no hacer cambios económicos y sociales necesarios para reducir los niveles de pobreza y hacer valer una mayor justicia social en el mundo" (p. 57).

14 Según dice Böhm (2013a, p. 12), lo que ocurre con estos procesos securitizantes es la aplicación del Derecho Penal del Enemigo (Jakobs) y de la criminología del otro extraño (Garland); según los cuales el sujeto que comete delitos no tiene los mismos derechos que los considerados ciudadanos. 
15 Así, pues, "el proceso securitizante resulta finalmente concluido cuando se reclama por parte de los agentes sociales e institucionales, en una suerte de retroalimentación discursiva, el combate de la amenaza existencial mediante la implementación de medidas excepcionales dentro del ámbito penal"' (Böhm, 2013a, p. 16).

16 Recientemente, se ha reconocido la constitucionalidad de la Ley de Medios Argentina; decisión esta inspiradora de que es posible, poco a poco, democratizar los medios de comunicación. Se ve que, más allá del Legislativo, el órgano Judicial también ha cumplido su papel en un proceso de resistencia (La Nación, 2013).

17 En ese punto, es interesante remitirse a las palabras de Zaffaroni proferidas en un Congreso realizado a inicios de 2013 en Río de Janeiro, intitulado: "Drogas: dos perigos da proibição à legalização". En esa ocasión, el Ministro de la Suprema Corte Argentina y gran jurista afirmó que "la sociedad no es suicida, ella es lo que es informada. La lucha hoy es por la información, por la comunicación".

18 Larrauri (2006, p. 19) defiende, como factor protector del populismo punitivo la "existencia de un cuerpo de técnicos que asesoran acerca de la eficacia e impacto de las reformas penales y que actúan como institución 'intermedia' entre la opinión pública y los políticos".

\section{Referencias}

Araujo, T. (2012) Maconha legalizada nos EUA. E agora? En Folha de S.Paulo, quince de noviembre. Recuperado de: http://www1.folha.uol.com.br/fsp/ opiniao/78092-maconha-legalizada-nos-eua-e-agora.shtml.

Barriuso, M. (2000). Las Naciones Unidas y la política internacional de control de drogas: factores para una inercia prohibicionista. En: Arana, X.; Márkez, I. y Vega, A. (Coord.), Drogas: Cambios sociales y legales ante el tercer milenio (139-162). Madrid: Dykinson.

Beck, U. (2001). ¿Qué es la globalización? Falacias del globalismo, respuestas a la globalización. (trad. de B. Moreno y M. R. Borràs) Buenos Aires: Paidós.

Beck, U. (2008). La sociedad del riesgo: Hacia una nueva modernidad (trad. de J. Navarro, D. Jiménez y M. R. Borràs), Barcelona: Paidós.

Böhm, M. L. (2013). Securitización. En Revista Penal, Julio (32), 72-90.

Böhm, M. L. (2013a). Políticas de seguridad y neoliberalismo. En: Fernández Steincko, A. Delincuencia, Finanzas y Globalización, Madrid: Centro de Investigaciones Sociológicas.

Brandariz, J. A. (2004). Itinerarios de evolución del sistema penal como mecanismo de control social en las sociedades contemporáneas. En 
Nuevos retos del Derecho penal en la era de la globalización, Faraldo Cabana, P., (dir), Brandariz García, J. A., Puente Aba, L.M., (coords), Valencia: Tirant lo Blanch.

Buzan, B., Waever, O. \& de Wilde, J. (1997). Security: a new framework for analysis. Boulder: Lynne Rienner Publishers.

Coitinho das Neves, T. C. (2013). El control penal de drogas y los medios de comunicación: aliados para un sistema autorreferencial. En Pérez, F., Memorias del III Congreso Internacional de Jóvenes Investigadores en Ciencias Penales, Salamanca: CISE.

De Carvalho, S. (2010) O Papel dos Atores do Sistema Penal na Era do Punitivismo (o exemplo privilegiado da aplicação da pena). Rio de Janeiro: Lumen Juris.

Díez, J. L. (2005). De la sociedad del riesgo a la seguridad ciudadana: un debate desenfocado. En Revista electrónica de ciencia penal y criminología, (7), 1-37.

Drug Policy Alliance (2014, 2-10). Marijuana Legalization and Regulation. Recuperado de: http://www.drugpolicy.org/marijuana-legalizationand-regulation.

Ericson, J. (2013). Medical Marijuana Returns Life To 6-Year-Old: Cannabis Oil Stopped Charlotte Figi's Severe Seizures. Recuperado de: http://www. medicaldaily.com/medical-marijuana-returns-life-6-year-old-cannabisoil-stopped-charlotte-figis-severe-seizures.

Gardner, F. (2013). Drugs. As Anecdotal Reports of Anti Cancer Effects from Cannabis 'Oil' Pile Up, Doctors Stress Need to Document Its Effects; Recuperado de: http://www.alternet.org/drugs/anecdotal-reportsanti-cancer-effects-cannabis-oil-pile-doctors-stress-need-document-its

Garland, D. (s.f.). La cultura del control: crimen y orden social en la cultura contemporánea, Barcelona: Gedisa.

Globo.com (2014, 2.5). Flórida é $22^{\circ}$ estado americado a permitir o uso medicinal da maconha; Recuperado de: http://g1.globo.com/mundo/ noticia / 2014/05/florida-e-22-estado-americano-permitir-usomedicinal-da-maconha.html

Hildebrand, A., Lagatta, P., Marques de Jesus, M. G., Thadeu, T. et al. (2011). Prisão Provisória e Lei de Drogas: um estudo sobre os flagrantes de tráfico de drogas na cidade de São Paulo. São Paulo: Núcleo de Estudos da violencia.

Hulsman, L. (1987). La política de drogas: fuente de problemas y vehículo de colonización y represión. En Nuevo Foro Penal, enero-marzo (35), 49-77. 
Lanación.com (2013, 29.10), La Corte Suprema declaró constitucional la Ley de Medios. Recuperado de: http://www.lanacion.com.ar/1633615-lacorte-suprema-declaro-constitucional-la-ley-de-medios

Larrauri, E. (2006). Populismo Punitivo...Y cómo resistirlo. En Jueces para la Democracia, (55), 15-22.

La Vanguardia. Internacional $(2013,11.12)$. Uruguay: primer país en legalizar la marihuana. Once de diciembre 2013. Recuperado de: http://www. lavanguardia.com/internacional/20131211/54395393175/uruguayprimer-pais-legalizar-comercio-marihuana.html.

Pariona, R. (2009). Sobre la necesaria legitimidad de las intervenciones penales, en: Julio B. J. Maier y J. B y Córdoba, G. E. (compiladores), ¿Tiene un futuro el Derecho Penal? Buenos Aires: Ad Hoc. 155-174.

Pérez, A. I. (2007) La seguridad como fundamento de la deriva del Derecho Penal Postmoderno. Madrid: Iustel.

San Martín, D. (2006). Retórica y gobierno del riesgo. La construcción de la seguridad en la sociedad (neoliberal) del riesgo, en: Bernuz/Pérez, La tensión entre la libertad y seguridad. La Rioja: Universidad de La Rioja.

Wacquant, L. (2000). Las cárceles de la miseria, Madrid: Alianza.

Williams, M. C. (1998). Modernity, Identity and Security: A Comment on the 'Copenhagen Controversy', en: Review of International Studies 24, 433-437. 